
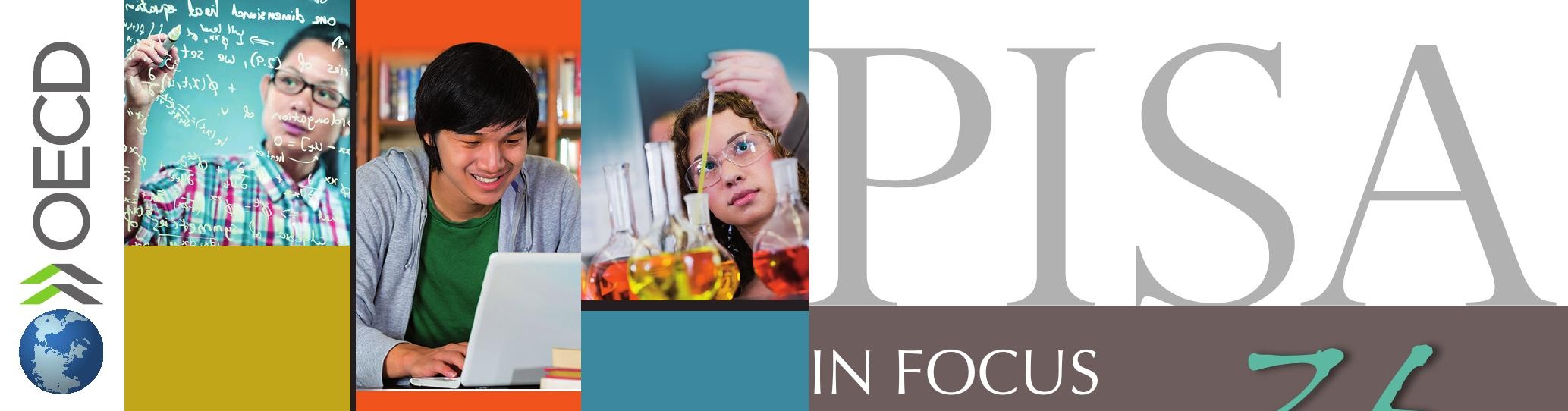

education data education evidence education policy education analysis education statistics education data education evidence

\title{
Do parents' occupations have an impact on student performance?
}

- Students whose parents work in professional occupations generally outperform other students in mathematics, while students whose parents work in elementary occupations tend to underachieve compared to their peers.

- The strength of the relationship between parents occupations and student performance varies considerably across countries: for example, when it comes to mathematics performance, the children of cleaners in Shanghai-China outperform the children of professionals in the United States, and the children of professionals in Germany outperform the children of professionals in Finland, on average.

- Finland and Japan achieve high levels of performance by ensuring that the children of parents who work in elementary occupations are given the same education opportunities and the same encouragement as the children of professionals.

How much can we infer about a student's performance in school by looking at what his or her parents do for a living? To find out, PISA 2012 asked participating students about their parents' occupations. The students' responses were then coded into an internationally comparable classification that allows for identifying individuals working in similar industries, on similar tasks, with the same types of responsibilities. For example, the classification defines the following nine major occupational groups ordered according to the levels of skills that are demanded in those occupations. Managers are considered the most highly-skilled, followed by professionals; technicians and associate professionals; clerical support workers; service and sales workers; skilled agricultural, forestry and fishery workers; craft and related trades workers; plant and machine operators and assemblers; and workers in elementary occupations.

Within each group, individuals are classified according to the field in which they work. For example, professionals are categorised as health professionals, teaching professionals, science professionals or business and administration professionals. 

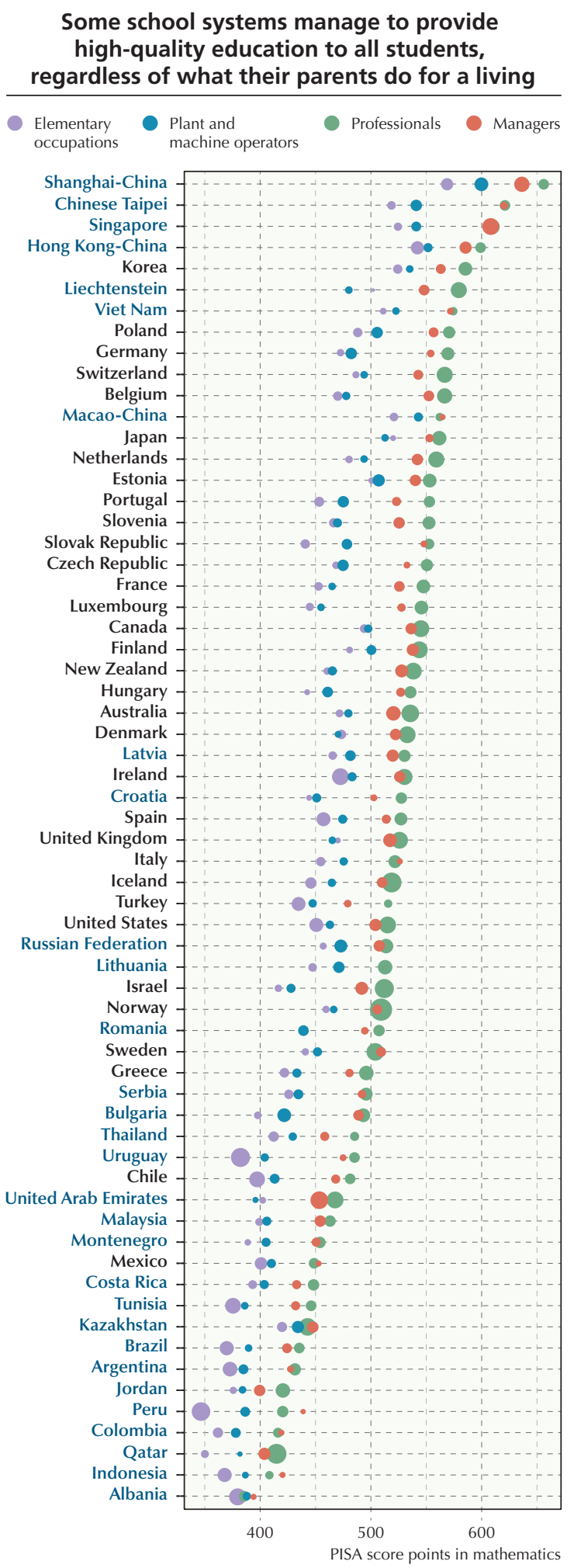

The size of the dots in the figure corresponds to the relative size of the population of students whose parents work in that occupation: the larger the dot, the larger the number of students who reported that at least one of their parents works in that occupation; the smaller the dot, the smaller the number of students who that occupation; the smaller the dot, the smaller the number of students who

Results correspond to the average performance of students who have at least one parent who works in a specific occupation.
Parents' occupations are associated with student performance...

In most countries and economies, children whose parents work as professionals have, on average, the best results in mathematics. Colombia, Indonesia, Italy, Mexico, Peru and Sweden are the exceptions: in these countries, the children of managers score the highest in mathematics. The gap in performance between the children of professionals and other students tends to be widest in mathematics and narrower in reading.

\section{and the share of students whose parents} work in a particular occupation has an impact on overall country performance.

PISA results reveal that where countries/economies stand in comparison to each other in mathematics performance is partly influenced by performance gaps related to parents' occupations and by the structure of the labour market. For example, Finland's performance in mathematics is better than that of Germany. However, in Germany, the children of professionals are among the world's best performers in mathematics, and outperform Finnish children of professional parents by a wide margin. At the same time, in Finland, the children of parents who work in manual occupations - craft and related trades workers; plant and machine operators and assemblers; and elementary occupations - outperform German students whose parents work in these occupations. The relative ranking of the two countries is determined by the relative share of the two groups of students: in both countries, fewer students have parents who work as professionals and more students have parents who work in manual occupations.

The classification of occupations in PISA 2012 was based on the ISCO 08 (International Standard Classification of Occupations) classification developed by the International Labour Organization to compare occupations across different countries. The categories are: 1 - Managers; 2 - Professionals; 3 - Technicians and associate professionals; 4 - Clerical support workers; 5 - Service and sales workers; 6 - Skilled agricultural, forestry and fishery workers; 7 - Craft and related trades workers; 8 - Plant and machine operators and assemblers; 9 - Workers in elementary occupations. 


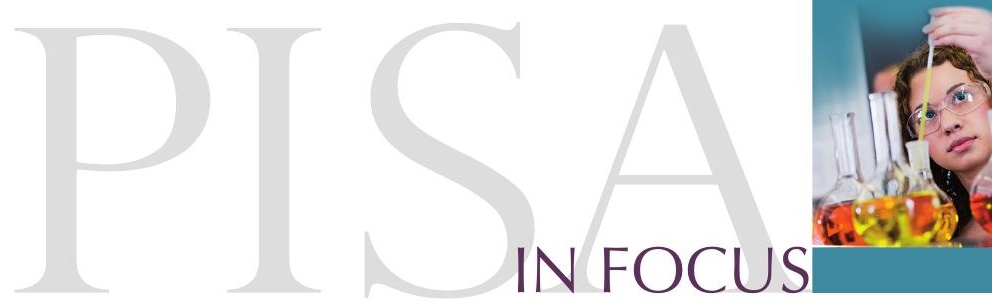

Student performance in mathematics in Germany and Finland, by parents' occupations

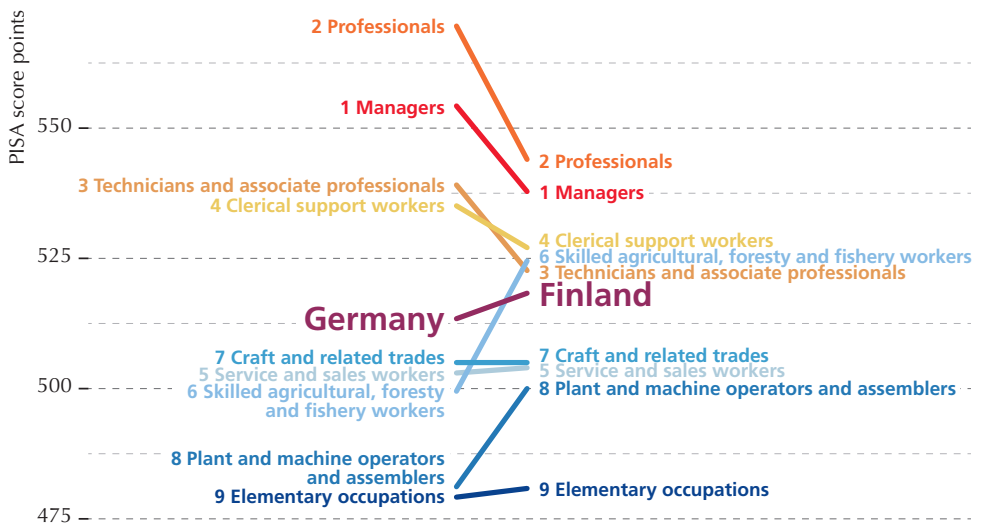

Student performance in mathematics in the United States, Finland, Germany and Shanghai-China, by parents' occupations

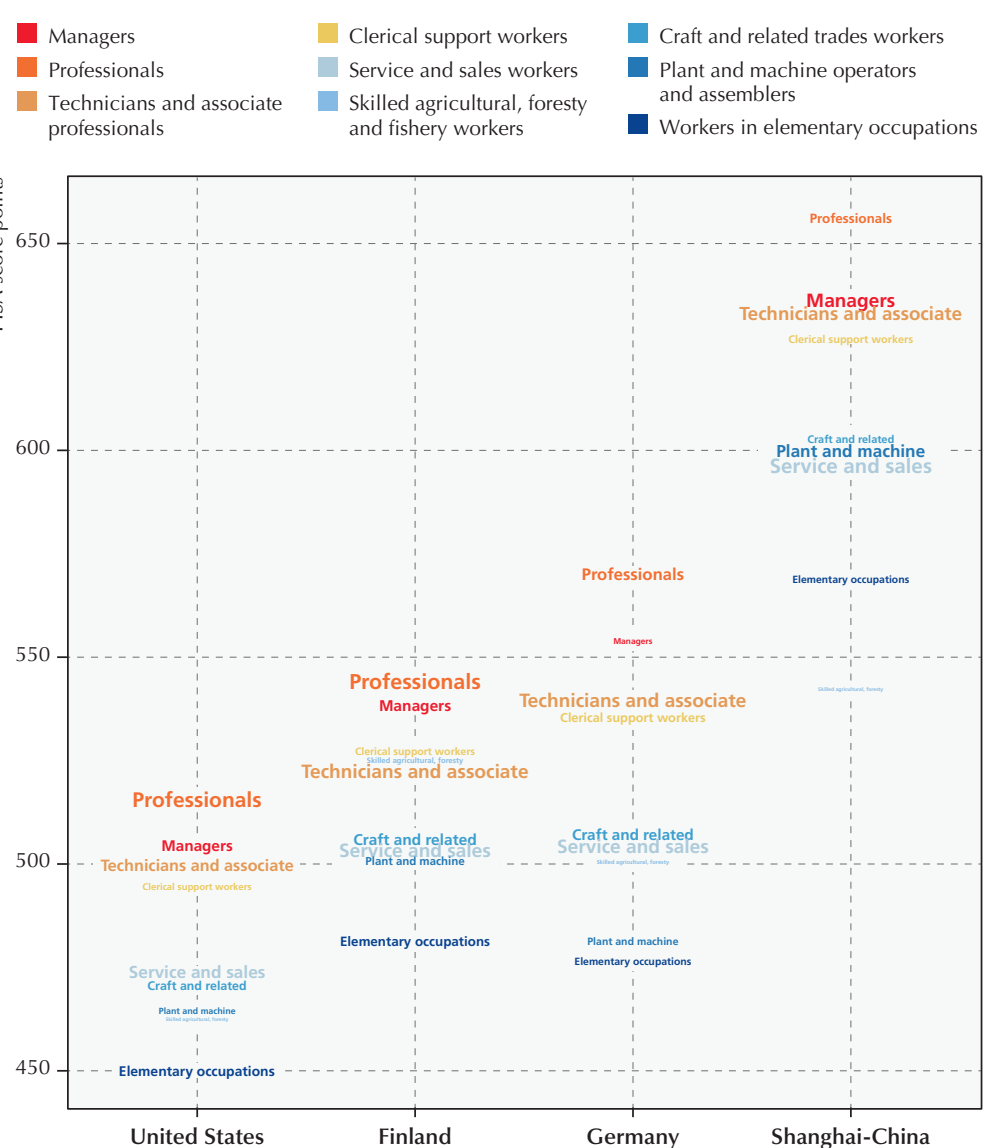

PISA unveils a new, interactive tool to explore the relationship between performance and parents' occupations.

PISA is launching an interactive, web-based application that allows anyone to explore and compare the relationship between student performance in reading, mathematics and science and parents' occupations in PISA-participating countries and economies.

Explore the relationship between parents' occupations and student performance at http://beta.icm.edu.pl/PISAoccupations2012/

PISA finds that France and New Zealand perform around the OECD average in mathematics, but have above-average inequity in education: the performance gap between the children of skilled workers and those of unskilled workers is among the largest. By contrast, the relative high performance of Finland, Hong-Kong and Korea stems from below-average levels of inequity. Germany is not among PISA's strongest performers overall because, while the children of professionals in Germany are among the world's best performers in mathematics, the large majority of students whose parents work in manual occupations perform very poorly.

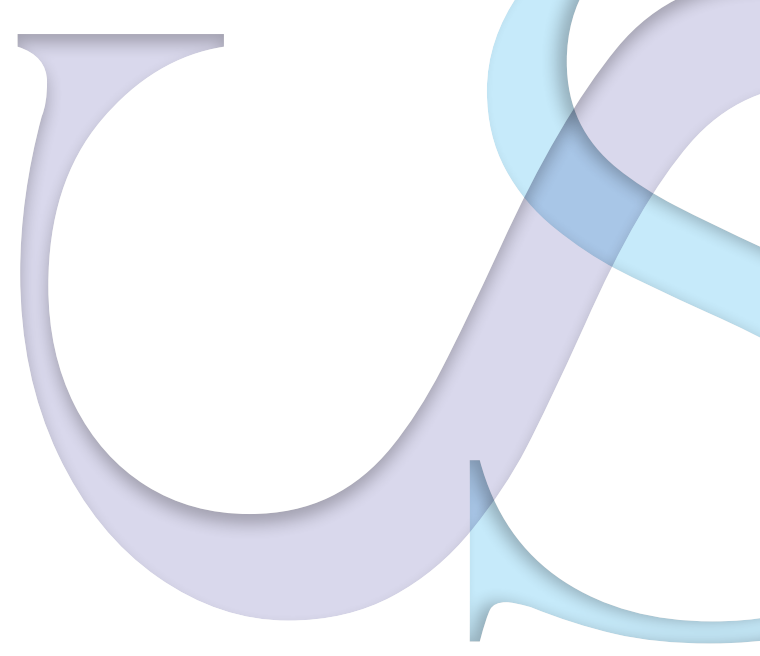




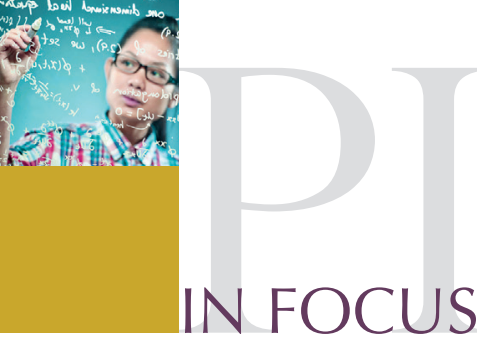

Student performance in mathematics in Singapore and the United Kingdom, by parents' occupations

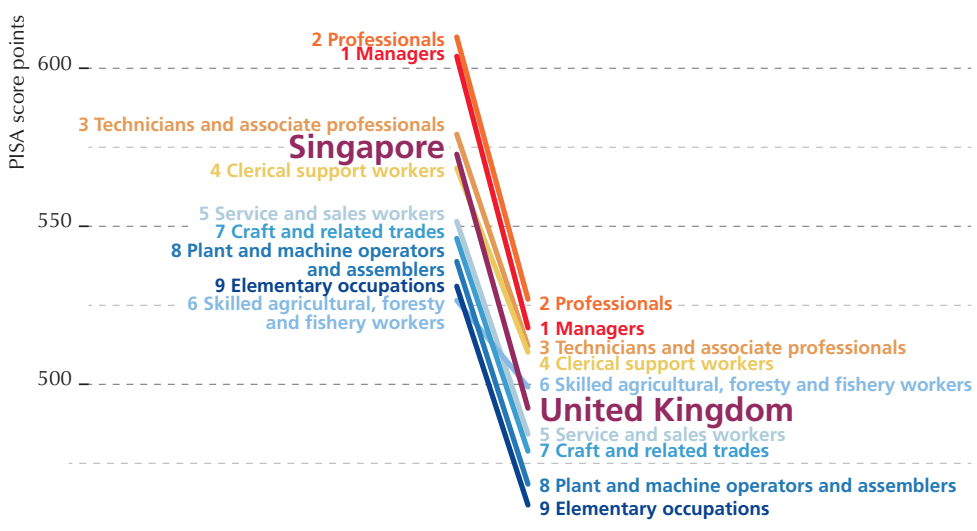

Student performance in mathematics in Shanghai-China and the United States, by parents' occupations

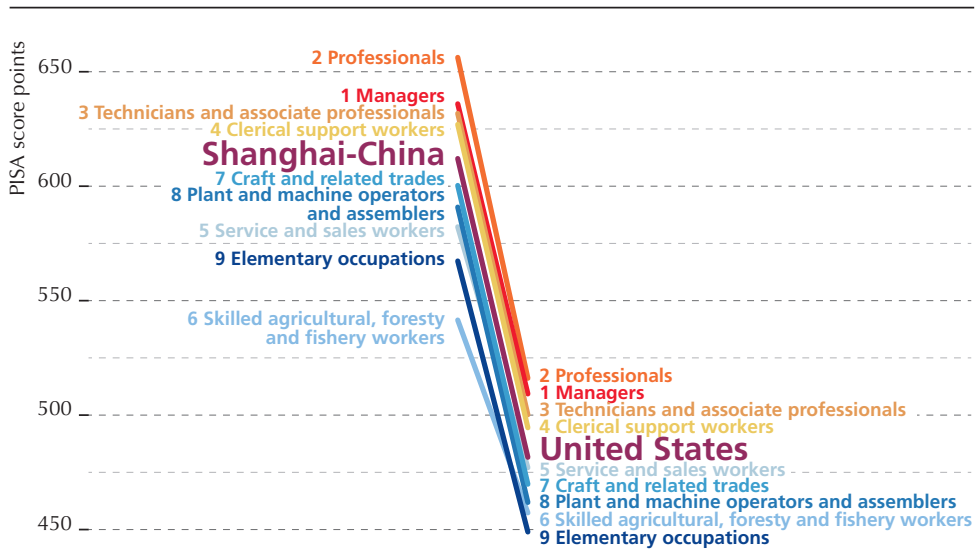

PISA also reveals that in the United States and the United Kingdom, where professionals are among the highest-paid in the world, students whose parents work as professionals do not perform as well in mathematics as children of professionals in other countries - nor do they perform as well as the children in Shanghai-China and Singapore whose parents work in manual occupations.

The bottom line: While there is a strong relationship between parents' occupations and student performance, the fact that students in some education systems, regardless of what their parents do for a living, outperform children of professionals in other countries shows that it is possible to provide children of factory workers the same high-quality education opportunities that children of lawyers and doctors enjoy.

\section{For more information}

Contact Przemyslaw Biecek (przemyslaw.biecek@gmail.com) or Francesca Borgonovi (Francesca.borgonovi@oecd.org) Przemyslaw Biecek developed the Occupations@PISA2012 application as part of his Thomas J. Alexander Fellowship in the Directorate for Education and Skills at the OECD.

\section{Visit}

www.pisa.oecd.org www.oecd.org/pisa/infocus Education Indicators in Focus Teaching in Focus

Coming next month

Do students have the drive to succeed? 